\title{
Bir oksalat hassasiyet gidericinin uzun dönem bağlanma dayanımı üzerine etkisi*
}

\author{
Tuğba Toz Akalın ${ }^{1}$, Arlin Kiremitçi², Saadet Gökalp², Zeynep Yenen ${ }^{3}$
}

Selcuk Dent J, 2016; 3: 15-19

Başvuru Tarihi: 23 Kasım 2015 Yayına Kabul Tarihi: 09 Mart 2016

\section{Öz \\ Bir oksalat hassasiyet gidericinin uzun dönem bağlanma dayanımı üzerine etkisi}

Amaç: $\mathrm{Bu}$ in vitro çalışmanın amacı bir oksalat hassasiyet gidericinin, farklı adeziv prosedürlerle dentin dokusuna uygulanan bir rezin kompozitin uzun dönem bağlanma dayanımı (3 yıl) üzerine etkisinin değerlendirilmesidir.

Gereç ve Yöntemler: Kırk adet çekilmiş insan molar dişi bukkal yüzeyleri açıkta kalacak biçimde, akrilik bloklara yerleştirilmiştir. Dişlerin bukkal yüzeyleri, düzgün dentin yüzeyi elde edilene kadar aşındırımıştır. Örnekler, rastgele dört gruba ayrılmıştır $(n=10)$. Grup 1: \%32 fosforik asit (Uni-etch), Oksalat hassasiyet giderici (BisBlock), asitle ve yıka adeziv (One Step Plus) uygulaması. Grup 2: Oksalat hassasiyet giderici, kendinden asitli adeziv (Tyrian Spe+One Step Plus) uygulaması. Grup 3: \%32 fosforik asit, asitle ve yıka adeziv uygulaması. Grup 4: kendinden asitli adeziv uygulaması. Yüzey hazırlığı işlemlerinin ardından, dentin yüzeylerine yerleştirilmiş teflon tüpler $(4 \times 2 \mathrm{~mm})$ hibrit rezin kompozit (TPH Spectrum) ile doldurulmuştur. Distile suda 3 sene süren bekleme periyodunun ardından örneklere, makaslama bağlanma dayanım testi uygulanmıştır. Veriler, Kruskall-Wallis testi ve Conover metodu ile istatistiksel olarak analiz edilmiştir.

Bulgular: Kendinden asitli adeziv öncesi uygulanan oksalat hassasiyet giderici (Grup 2) bağlanma dayanımını istatistiksel olarak anlamlı derecede düşürmüştür $(p<0,05)$. Grup 1 , Grup 3 ve Grup 4 arasında istatistiksel olarak anlamlı bir farklılık gözlenmemiştir.

Sonuç: Oksalat hassasiyet giderici uygulaması kendinden asitli adezivlerin dentin dokusuna uzun dönem bağlanma dayanımını negatif olarak etkileyebilir.

\section{ANAHTAR KELIMELER}

Adezivler, bisblock, dentin

Klinisyenlerin sıklıkla karşılaştığı problemlerden biri olarak kabul edilen ve açığa çıkan dentin kaynaklı, kısa süreli ve keskin ağrılar olarak tanımlanan aşırı dentin hassasiyeti hidrodinamik teori ile açıklanmıştır. $\mathrm{Bu}$ teoriye göre, dentin tübüllerinin tıkanması, Sıvı akışını ve dolayısı ile aşıı hassasiyeti engeller (Acar

\section{ABSTRACT \\ Effect of oxalate desensitizer on long-term bond strength to dentin}

Background: The aim of this in vitro study was to assess the influence of an oxalate desensitizer on long-term (3 years) bonding of a resin composite applied with different adhesive procedures strength to dentin.

Methods: Forty extracted human molars were embedded in acrylic resin with buccal surfaces positioned for surface treatment and composite bonding. The buccal surfaces were ground to obtain flat dentin surfaces $(n=40)$. They were randomly divided into four groups $(n=10)$. Group 1: $32 \%$ phosphoric acid (Uni-etch) etching, Oxalate desensitizer (BisBlock) application, etch\&rinse adhesive (One Step Plus) application. Group 2: Oxalate desensitizer, self-etch adhesive (Tyrian Spe + One Step Plus). Group 3: $32 \%$ phosphoric acid etching, etch\&rinse adhesive and Group 4: Self-etch adhesive. After the respective pretreatment sequences, a teflon tube $(4 \times 2 \mathrm{~mm})$ was attached to the dentin surfaces and filled with a hybrid resin composite (TPH Spectrum). Following storage in distilled water for 3 years, the specimens subjected to shear bond test. Data were analyzed using KruskallWallis test and pairwise comparisons were made by Conover method.

Results: The oxalate desensitizer application before self-etch adhesive (Group 2) use significantly decreased the bond strength to dentin $(p<0.05)$. There was no statistically significant difference among group 1, Group 3 and Group 4.

Conclusion: The oxalate desensitizer application might negatively affect the long term shear bond strength of self-etch adhesives to dentin.

\section{KEYWORDS}

Adhesives, bisblock, dentin

ve ark. 2014). Dentin hassasiyet gidericileri, geliştirilmelerinden itibaren adeziv sistem (bonding ajan) ya da difüzyon bariyeri gibi birçok formlarda üretilmektedirler. Dentin aşırı hassasiyeti tedavisinde sıklıkla kullanılan bu materyaller, aktivitelerine göre antiinflamatuar ilaçlar, protein çökelticiler, tübül tıkayıcı

\footnotetext{
* Bu çalışma 12-19 Eylül 2009 tarihinde Münih, Almanya'da düzenlenen “International Association for Dental Research, Continental European Division" isimli kongrede poster olarak sunulmuştur.

${ }^{1}$ İstanbul Medipol Üniversitesi Diş Hekimliği Fakültesi Restoratif Diş Tedavisi Anabilim Dalı, İstanbul

2 Hacettepe Üniversitesi Diş Hekimliği Fakültesi Restoratif Diş Tedavisi Anabilim Dalı, Ankara

${ }^{3}$ Serbest Hekim, Ankara
} 
ajanlar ve lazer tedavisi olarak sınıflandırılabilir (Huh ve ark. 2008). Sodyum Florür ya da Potasyum oksalat gibi kimyasal desensitize edici ajanlar dentin tübüllerinin tıkanması ile etkinliklerini gösterirler (Acar ve ark. 2014).

Oksalat hassasiyet giderici (BisBlock, Bisco, Schaumburg, ABD), asidik rezin içermeyen oksalat potasyum solüsyonu veya jeli olarak diş hekimlerinin kullanımına sunulmuştur (Huh ve ark. 2008). Adeziv prosedürlerden önce dentin dokusuna uygulanan oksalat hassasiyet gidericiler, rezin dentin arayüzü ve adeziv tabaka arasında sıvı akışını engelleyen alternatif bir tedavi yöntemi olarak kabul görmüşlerdir (Tay ve ark. 2003). Oksalat solüsyon ya da jeller, dentin dokusu içeriğindeki iyonize kalsiyum ile reaksiyona girerek, çözünmeyen kalsiyum oksalat kristallerini oluştururlar (Pashley ve ark. 1978). Smear tabakası ile örtülü dentin yüzeyine uygulandıklarında ise bu tabaka ile yer değiştirmiş bir kristal tabaka izlenir (Huh ve ark. 2008). Dentin tübüllerinde oluşan kalsiyum oksalat kristalleri, dentine sıvı akışını azaltır ve dolayısı ile hassasiyetin azalmasına neden olur (de Andrade e Silva ve ark. 2007). Oksalat hassasiyet gidericilerin dentin tübüllerini oksalat kristalleri ile tıkamasının farklı bir sonucu ise klinisyenlerin adeziv işlemler sırasında asit uygulanmış dentin dokusu üzerinde daha kolay nem kontrolü sağlaması olarak açıklanmıştır. Bir teori olarak oksalat kristallerinin, dentine SIVI akışını azaltarak adezivlerin polimerizasyonu için uygun koşulların elde edilmesine olanak sağladığı da belirtilmiştir (Pashley ve ark. 2001). Asit uygulanmış dentin yüzeyine uygulandığı durumlarda oksalat kristallerinin, dentin tübüllerinin 5-10 $\mu \mathrm{m}$ altında tıkanmaya neden olduğu ve yüzeyin bağlanmaya uygun kaldığı da bilinmektedir. Sonuç olarak oksalat hassasiyet gidericilerin asitle ve yıka adezivlerin bağlanma dayanımlarında düşüşe neden olmadığı rapor edilmiştir (Tay ve ark. 2003). Bununla birlikte oksalat hassasiyet gidericilerinin adezivlerin bağlanma dayanımı üzerine etkisi ile ilgili veriler sınırlıdır. Bir in vitro araştırmada, oksalat solüsyonu uygulamasının ardından dentin yüzeyinde kalan oksalik asit gibi artıkların, adezivin polimerizasyonunu ve bağlanma performansını olumsuz olarak etkiledikleri de bildirilmiştir (de Andrade e Silva ve ark. 2010).

Kendinden asitli adeziv sistemler, diş dokularına yıkama gerektirmeksizin eşzamanlı olarak bağlanma sağlarlar. Bu nedenle dentin yüzeyinde hassasiyet giderici artığı kalma olasılığını ortaya çıkarırlar. Hassasiyet gidericinin adeziv sistem ile temasının bağlanma üzerinde olumsuz bir etki ile sonuçlanabileceği belirtilmiştir (de Andrade e Silva ve ark. 2010). Literatür bilgilerimize göre, oksalat hassasiyet gidericilerin kendinden asitli ve asitle ve yıka adeziv sistemlerin bağlanma dayanımı üzerine olan etkisinin bir arada araştırıldığı bir çalışma bulunmamaktadır. Bu çalışmanın amacı, oksalat hassasiyet gidericilerin asitle ve yıka ve kendinden asitli olmak üzere iki farklı teknik ile uygulanan adeziv sistemin dentin yüzeyine uzun dönem bağlanma dayanımına etkisinin değerlendirilmesidir. Çalışmanın hipotezi, oksalat hassasiyet gidericilerin kendinden asitli ve asitle ve yıka sitemlerin uzun dönem bağlanma dayanımlarını olumsuz yönde değiştirdiğidir.

\section{GEREÇ VE YÖNTEM}

\section{Dentin yüzeylerinin hazırlanması}

$\mathrm{Bu}$ in vitro araştırmada, 40 adet çürüksüz daimi molar dis kullanıldı. Diş yüzeylerindeki yumuşak doku artıkları temizlendikten ve timol solusyonunda $(\% 0,2)$ en fazla 1 hafta dezenfekte edildikten sonra $20^{\circ} \mathrm{C}$ 'de distile suda bekletildi. Dişler, mine-sement birleşim hattının 2-3 mm apikalinden düşük hızda, su soğutması altında elmas testere (Isomet, Buehler, Lake Bluff, IL, ABD) ile kron ve kök olarak iki kısma ayrıldı. Köklerinden ayrılmış diş kronları, bukkal yüzeyleri açıkta kalacak şekilde akrilik rezin bloklara (Meliodent, Heraeus Kulzer, Dormagen) gomuldü. Açıkta bırakılan bukkal yüzeyler 120, 240, 400 ve 600 gritlik silikon karbit zımpara ile su altında düzgün ve standart dentin dokusu elde edilene kadar aşındırıldı. Distile su ile yıkanan örneklerin dentin yüzeyleri, çatlak veya hipoplastik kusurlar açısından stereomikroskopta (Leica, MZ 12, Leica AG, CH-9435 Heerbrugg, Isvicre) incelendi.

\section{Örneklerin hazırlanması}

Örnekler rastgele dört gruba ayrıldı $(n=10)$ ve adeziv restorasyonlar, hazırlanan dentin yüzeyleri üzerine üretici firma önerileri doğrultusunda uygulandı. Çalışmada kullanılan adeziv materyaller ve içerikleri Tablo 1'de verilmiştir.

Tablo 1.

Araştırmada kullanılan materyaller ve içerikleri

\begin{tabular}{|c|c|c|c|}
\hline Materyaller & Materyal türü & Materyal içeriği & Üretici firma \\
\hline BisBlock & $\begin{array}{l}\text { Oksalat } \\
\text { desensitizer }\end{array}$ & $\begin{array}{l}\text { Oksalik asit, potasyum tuzu } \\
\text { ve su }\end{array}$ & $\begin{array}{l}\text { Bisco Inc, } \\
\text { Schaumburg, } \\
\text { IL, ABD }\end{array}$ \\
\hline One Step Plus & $\begin{array}{l}\text { Asitle ve yıka } \\
\text { adeziv sistem }\end{array}$ & $\begin{array}{l}\text { BPDM, Bis-GMA, HEMA, } \\
\text { aseton, başlatıcılar, } \\
\text { floroalimünosilikat cam } \\
\text { doldurucular }\end{array}$ & $\begin{array}{l}\text { Bisco Inc, } \\
\text { Schaumburg, } \\
\text { IL, ABD }\end{array}$ \\
\hline Tyrian Spe & $\begin{array}{l}\text { Kendinden } \\
\text { asitli primer }\end{array}$ & $\begin{array}{l}\text { Primer A: } 0.5 \text { timol mavisi, } \\
\text { etanol, su } \\
\text { Primer B: AMPS, Bis-MEP } \\
\text { (Bis[2-metil] fosfat), TPO ve } \\
\text { etanol }\end{array}$ & $\begin{array}{l}\text { Bisco Inc, } \\
\text { Schaumburg, } \\
\text { IL, ABD }\end{array}$ \\
\hline $\begin{array}{l}\text { TPH } \\
\text { Spectrum }\end{array}$ & $\begin{array}{l}\text { Mikrohibrit } \\
\text { rezin kompozit }\end{array}$ & Bis-GMA, TEGDMA & $\begin{array}{l}\text { Dentsply, } \\
\text { ABD }\end{array}$ \\
\hline
\end{tabular}


$\mathrm{Bu}$ in vitro değerlendirmede tercih edilen adeziv sistem, One Step Plus'dır (Bisco Inc, Schaumburg, IL, ABD).Asit uygulamasının (Uni-etch, Bisco Inc, Schaumburg, IL, ABD) ardından, asitle ve yıka adeziv sistem esasına uygun olarak kullanılabilir bir materyaldir. Aynı zamanda öncesinde kendinden asitli bir primer (Tyrian Spe, Bisco Inc, Schaumburg, IL, ABD) ile asit uygulaması gerektirmeksizin kendinden asitli adeziv sistem uygulamaları esas alınarak da kullanılabilir.

Grup 1: Dentin yüzeyleri, 15 saniye boyunca uygulanan asit (Uni-etch) sonrasında $15 \mathrm{sn}$ yıkanarak hafif hava spreyi ile hafifçe kurutuldu. Oksalat hassasiyet giderici (BisBlock, Bisco Inc, Schaumburg, IL, ABD) kurutulan dentin yüzeylerine 30 sn boyunca uygulandı ve yüzeyler yıkandı. Dentin yüzeylerinin nemli bağlanma tekniği ile hafifçe kurutulmasının ardından, adeziv sistem (One Step Plus) etch\&rinse adeziv sistemin uygulanması esas alınarak ince bir tabaka halinde sürülüp hafif hava spreyi uygulanarak 20 sn ışıkla (Hilux 200, Benlioğlu, Ankara, Türkiye) polimerize edildi.

Grup 2: Oksalat hassasiyet gidericinin 30 sn boyunca dentin yüzeylerine uygulanması, yıkanması ve yüzeyin hafifçe kurutulmasını takiben kendinden asitli primer (Tyrian Spe) bu yüzeylere fırça yardımı ile 20 sn boyunca sürtülerek uygulandı. On sn bekleme süresinin ardından hafifçe hava sıkılmasının ardından adeziv sistem (One Step Plus), kendinden asitli adeziv sistemin uygulanması esas alınarak ince bir tabaka halinde sürüldü. Hafif hava spreyi uygulandı ve 20 sn ışıkla polimerize edildi.

Grup 3: Dentin yüzeyleri, 15 sn boyunca uygulanan asit (Uni-etch) sonrasında 15 saniye yıkanarak hafif hava spreyi ile kurutuldu. Adeziv sistem (One Step Plus, Bisco Inc, Schaumburg, IL, ABD) etch\&rinse adeziv sistemin uygulanması esas alınarak bir tabaka halinde sürüldü, hafif hava spreyi uygulandı ve 20 sn ışıkla polimerize edildi.

Grup 4: Kendinden asitli primerin (Tyrian Spe) dentin yüzeyine fırça yardımı 20 sn boyunca sürtülerek uygulandı. On sn bekleme süresinin ardından hava sıkılmasının ardından adeziv sistem (One Step Plus), kendinden asitli adeziv sistemin uygulanması esas alınarak ince bir tabaka halinde sürüldü. Hafif hava spreyi uygulandı ve 20 sn ışıkla polimerize edildi.
Mikrohibrit kompozit rezin (TPH Spectrum, Dentsply, $A B D)$, adeziv uygulanan dentin yuzeylerine özel bir aparat yardımı ile $4 \mathrm{~mm}$ çapında ve $2 \mathrm{~mm}$ yüksekliğinde olacak şekilde iki tabaka olarak uygulandı ve her bir tabaka 40 sn Işıkla polimerize edildi. Dişler, $37^{\circ} \mathrm{C}$ 'de 24 saat süre ile distile suda bekletildikten sonra, kompozit rezin diş birleşim bölgelerine Universal Test Cihazında (Lloyd LRX Universal, Lloyd Instruments, Fareham, Hants, Ingiltere ), bıçak şeklindeki çelik bir uçla $1 \mathrm{~mm} /$ dak kafa hızında yük uygulandı. Kompozitin dentinden koptuğu andaki değerler en yüksek kırılma kuvvetinin $(\mathrm{N})$ bağlanma alanına (çap 4 $\mathrm{mm}$ ) bölünmesi ile hesaplandı ve megapaskal ( $\mathrm{MPa}$ ) cinsinden kaydedilerek veriler Kruskall-Wallis test ve Conover metodu ile istatistiksel olarak analiz edildi.

\section{BULGULAR}

Bu çalışmadan elde edilen bağlanma dayanım değerleri Tablo 2'de gösterilmiştir. Adeziv sistem'in asit uygulaması (Grup 3) ya da kendinden asitli primer (Grup 4) ile uygulanması sonrasında dentine olan bağlanma dayanım değerleri arasındaki farklııklar istatistiksel olarak anlamlı bulunmamıştır $(p>0.05)$. Oksalat hassasiyet giderici uygulanmasının ardından, adezivin asitle ve yıka adeziv uygulanması esas alınarak uygulandığı grupta (Grup 1) gözlenen bağlanma dayanımı değerleri de Grup 3 ve Grup 4 'den farklı olarak gözlenmemiştir $(p>0.05)$. One Step Plus'ın, kendinden asitli adeziv sistem uygulaması esas alınarak kendinden asitli primer (Grup 2) ile kullanılması öncesinde uygulanan oksalat hassasiyet gidericinin (BisBlock), bağlanma dayanımı değerlerini istatistiksel olarak anlamlı derecede düşürdüğü gözlenmiştir $(p<0.05)$.

Tablo 2.

\section{Araştırmada kullanılan materyaller ve içerikleri}

\begin{tabular}{|c|c|c|c|c|c|}
\hline Gruplar & & $\mathbf{n}$ & $\begin{array}{l}\text { Ortanca } \\
\text { (MPa) }\end{array}$ & $\begin{array}{l}\text { Minimum } \\
\text { (MPa) }\end{array}$ & $\begin{array}{l}\text { Maksimum } \\
\text { (MPa) }\end{array}$ \\
\hline Grup 1 & $\begin{array}{l}\text { \%32 asit } \\
\text { uygulaması + } \\
\text { oksalat } \\
\text { hassasiyet } \\
\text { giderici + One } \\
\text { Step Plus }\end{array}$ & 10 & $10,77^{\mathrm{a}}$ & 5,58 & 14,95 \\
\hline Grup 2 & $\begin{array}{l}\text { kendinden asitli } \\
\text { primer (Tyrian } \\
\text { Spe) + oksalat } \\
\text { hassasiyet } \\
\text { giderici + One } \\
\text { Step Plus }\end{array}$ & 10 & $4,78^{b}$ & 1,79 & 9,23 \\
\hline Grup 3 & $\begin{array}{l}\% 32 \text { asit } \\
\text { uygulaması }+ \\
\text { One Step Plus }\end{array}$ & 10 & $9,94^{\mathrm{a}}$ & 3,23 & 27,12 \\
\hline Grup 4 & $\begin{array}{l}\text { kendinden asitli } \\
\text { primer (Tyrian } \\
\text { Spe) + One Step } \\
\text { Plus }\end{array}$ & 10 & $9,56^{\mathrm{a}}$ & 6,57 & 16,46 \\
\hline
\end{tabular}

Farklı üst indise sahip gruplar istatistiksel olarak farklı bulunmuştur. 


\section{TARTIȘMA}

Diş dokusuna etkili bir bağlanmanın, restorasyonun marjinal uyumunun daha iyi sağlanabilmesine ve operasyon sonrası duyarlıığın engellenmesindeki en önemli faktör olduğu mutlaka göz önünde bulundurulmalıdır (Shafiei ve Memarpour 2013). Bu bağlanma, hibrit tabaka veya dentin içerisine uzanan rezin tag oluşumu ile özetlenen, adeziv sistemlerin diş dokusuna mikromekanik bağlantısı olarak tanımlanır (Ferrari ve ark. 2000). Preparasyon sonrasında, açığa çıkan dentin tübüllerinin farkı şekillerde tıkanabildiği görüşleri vardır. İlk görüş, smear tabakasının varlığı ile açıklanabilir. Pashley (Pashley 1984), smear tabakasının dentin geçirgenliğini asit uygulanmış dentin dokusu ile karşılaştıııldığında, \%98 oranında azalttığııı bildirmiştir. Kerns ve arkadaşları (Kerns ve ark. 1991) ise mikrosızıntı varlığında çevresel asitlerin, smear tabakasını ortadan kaldırabildiğini vurgulamışlardır. İkinci yaklaşım, adeziv sistemlerin uygulanmasıdır. Smear tabakasına uygulanan adeziv sistemler, mekanik retansiyonu arttıllar ve asit ile sivı iletimini engellerler (Ferrari ve ark. 1999). Bununla birlikte gösterdikleri koruyucu etkinin ne kadar süreli olacağı öngörülememektedir. Üçüncü yaklaşım oksalat partiküllerinin tercih edilmesidir. Oksalatlar gibi desensitize edici ajanlar, operasyon sonrası oluşan ya da mevcut aşırı dentin hassasiyetini engellemek için uygulanan materyallere örnek olarak gösterilebilirler (Christensen 2002). Pashley ve Galloway (Pashley ve Galloway 1985). Oksalat ile muamele edilmiş dentin dokusunda hidrolik iletkenliğin düştüğünü ve dentin hassasiyetinin azaldığını bildirmişlerdir. Bu verilere ek olarak, oksalat hassasiyet gidericilerin, adeziv sitemlerin bağlanma mekanizmalarını etkileyebileceği de bildirilmiştir. Bazı araştırmalarda adeziv sistemlerin, oksalat ile tedavi edilmiş dentin yüzeylerine bağlanmalarının daha düşük olduğu belirtilmiştir (Al Qahtani ve ark, 2003). Bu çalışmada oksalat hassasiyet gidericinin (BisBlock) asitle ve yıka ve kendinden asitli olmak üzere iki farklı teknik ile uygulanan adeziv sistemin dentin yüzeyine uzun dönem bağlanma dayanımına etkisinin değerlendirilmiştir. Oksalat hassasiyet gidericinin sadece kendinden asitli primer uygulandığı grupta bağlanma dayanımını düşürdüğü gözlenmiş ve çalışmanın hipotezi kısmen kabul edilmiştir.

Oksalat hassasiyet gidericilerin uygulanması sonrasında, diş dokularının yıkanmasına rağmen arda kalma olasılığı bulunmaktadır. Oksalik asitin kalsiyum ile reaksiyona girerek, dentin yüzeyinde kristal çökelmesine neden olabileceği ve adeziv polimerizasyonunu olumsuz olarak etkileyebileceği bildirilmiştir (de Andrade e Silva ve ark, 2010). Bu etkinin yanı sıra, asiditesine bağlı olarak bu materyallerin çökelen kristallere rağmen diş dokusunda ek bir demineralizasyon oluşturdukları da belirtilmektedir. Aşırı demineralizasyonun ise bağlanma dayanımını olumsuz yönde etkilediği de literatürde vurgulanmış ve bu düşüş, adeziv monomerlerin infiltrasyonu ve demineralizasyon derinliği arasındaki uyumsuzluk ile açıklanmıştır (Hashimoto ve ark. 2002). Bunlara ek olarak, asit uygulanmış yüzeylere oksalat hassasiyet giderici uygulanmasının, adeziv prosedür uygulanması sırasında ve sonrasında dentin sıvı akışını azalttığı bildirilmiştir. Adeziv içeriğinde bulunan çözücünün, buharlaşması sırasında osmotik basınç etkisi ile oluşan sıvı iletimini düşürdüğü, dolayısı ile adeziv ile sıvı temasını azalttığı gözlenmiştir. Bu durumun, hidrofilik adezivlerin zaman içerisinde sIVI emilimi ile bozulmasını sınırlandırabileceği de bildirilmiş ve bu yöntemin derin dentin çürüğü tedavisinde uygulanabilir olabileceği vurgulanmıştır (Yousry 2012).

Silva ve arkadaşları (de Andrade e Silva ve ark. 2010), oksalat hassasiyet gidericilerin bağlanma dayanımı üzerine etkilerini araştırdıkları çalışmalarında, bu materyallerin erken dönemde bağlanmayı olumsuz yönde etkilediğini bildirmişlerdir. Uzun dönem bağlanma dayanımlarını değerlendirdiklerinde ise, oksalat hassasiyet giderici uygulanan grupların bağlanma dayanımlarındaki düşüşün kontrol grupları ile karşılaştırıldığında daha yüksek olduğunu izlemişlerdir. $\mathrm{Bu}$ çalışma, One Step Plus adeziv sistemin asit ve kendinden asitli primer uygulaması olmak üzere iki farklı şekilde kullanıldığı ve oksalat hassasiyet giderici BiscoBlock'un bu adeziv prosedürler uygulandıktan sonra adezivin uzun dönem bağlanma dayanımına etkisinin değerlendirildiği bir araştırmadır. Literatürde belirtilmiş olan farklı sonuçlar dikkate alındığında, çalışmamızdan elde ettiğimiz bulgularımız, oksalat hassasiyet gidericilerin asit uygulanmış dentin yüzeyine uzun dönem bağlanma dayanımı üzerinde farklı bir etki göstermediği sonucuna ulaştırmıştır. Bununla birlikte oksalat hassasiyet giderici BiscoBlock'un, kendinden asitli primer Tyrian Spe sonrasında uygulanan adeziv One Step Plus'ın uzun dönemde bağlanma dayanımını düşürdüğü belirlenmiştir. $\mathrm{Bu}$ durum, yıkama aşamasının eliminasyonu ile arda kalan oksalik asit varlığı ile ilişkilendirilebilir.

\section{SONUÇ}

Oksalat hassasiyet gidericiler, asit uygulanması ile karakterize asitle ve yıka adeziv uygulamaları sonrasında uzun dönem bağlanma dayanımını etkilemezken, asit uygulamaksızın kendinden asitli primer uygulanması sonrasında uzun dönem bağlanma dayanımı üzerinde olumsuz etki göstermiştir. 


\section{KAYNAKLAR}

Acar O, Tuncer D, Yuzugullu B, Celik C, 2014 The effect of dentin desensitizers and Nd:YAG laser pretreatment on microtensile bond strength of selfadhesive resin cement to dentin. J Adv Prosthodont, 6, 88-95.

Al Qahtani MQ, Platt JA, Moore BK, Cochran MA, 2003. The effect on shear bond strength of rewetting dry dentin with two desensitizers. Oper Dent, 28(3), 287-296.

Christensen GJ, 2002. Preventing postoperative tooth sensitivity in class I, II and V restorations. J Am Dent Assoc, 133(2), 229-231.

De Andrade e Silva SM, Malacarne-Zanon J, Carvalho RM, Alves MC, DeGoes MF, Anido-Anido A, Carrilho $M R$, 2007. Effects of a combined application of potassium oxalate gel/adhesive agent on dentin permeability in vitro. J Adhes Den, 9(6), 505-512.

De Andrade e Silva SM, Malacarne-Zanon J, Carvalho RM, Alves MC, DeGoes MF, Anido-Anido A, Carrilho MR, 2010. Effect of oxalate desensitizer on the durability of resin-bonded interfaces. Oper Dent, 111, 35(6), 610-617.

Ferrari M, Cagidiaco MC, Kugel G, Davidson CL, 1999. Clinical evaluation of a one-bottle bonding system for desensitizing exposed roots. Am J Den, 12(5), 243249.

Ferrari M, Mason PN, Vichi A, Davidson CL, 2000. Role of hybridization on marginal leakage and bond strength. Am J Den, 13(6), 329-336.

Hashimoto M, Ohno H, Kaga M, Sano H, Tay FR, Oguchi H, Araki Y, Kubota M, 2002. Over-etching effects on micro-tensile bond strength and failure patterns for two dentin bonding systems. J Den, 30(23), 99-105.

Huh JB, Kim JH, Chung MK, Lee HY, Choi YG, Shim JS, 2008. The effect of several dentin desensitizers on shear bond strength of adhesive resin luting cement using self-etching primer. J Dent, 36(12), 1025-1032.

Kerns DG, Scheidt MJ, Pashley DH, Horner JA, Strong SL, Van Dyke TE, 1991. Dentinal tubule occlusion and root hypersensitivity. J Periodontol, 62(7), 421-428.

Pashley DH, Livingston MJ, Reeder OW, Horner J, 1978. Effects of the degree of tubule occlusion on the permeability of human dentine in vitro. Arch Oral Biol, 23(12), 1127-1133.
Pashley $\mathrm{DH}$, 1984. Smear layer: physiological considerations. Oper Dent, 3, 13-29.

Pashley DH, Galloway SE, 1985. The effects of oxalate treatment on the smear layer of ground surfaces of human dentine. Arch Oral Biol, 30(10), 731-737.

Pashley DH, Carvalho RM, Pereira JC, Villanueva R, Tay FR, 2001. The use of oxalate to reduce dentin permeability under adhesive restorations. Am J Dent, 14(2), 89-94.

Shafiei F, Memarpour M, 2013. Effect of surface pretreatment with two desensitizer techniques on the microleakage of resin composite restorations. Lasers Med Sci, 28(1), 247-251.

Tay FR, Pashley DH, Mak YF, Carvalho RM, Lai SC, Suh $\mathrm{BI}, 2003$. Integrating oxalate desensitizers with total-etch two-step adhesive. J Dental Res, 82(9), 703-707.

Yousry MM, 2012. Effect of re-etching oxalateoccluded dentin and enamel on bonding effectiveness of etch-and-rinse adhesives. J Adhes Dent, 14(1), 31-38.

\section{Yazışma Adresi:}

Yrd. Doç. Dr. Tuğba TOZ AKALIN

İstanbul Medipol Üniversitesi

Diş Hekimliği Fakültesi Restoratif Diş Tedavisi AD

İstanbul, Türkiye

Tel : + 905433242554

Faks : + 902125210426

E-mail: ttoz@medipol.edu.tr 